\title{
BMJ Open Weight change after antiretroviral therapy initiation among adults living with HIV in Northwest Ethiopia: a longitudinal data analysis
}

\author{
Animut Alebel (D) ,,2 Daniel Demant, ${ }^{2,3}$ Pammla Margaret Petrucka, ${ }^{4,5}$ \\ David Sibbritt ${ }^{2}$
}

To cite: Alebel A, Demant D, Petrucka PM, et al. Weight change after antiretroviral therapy initiation among adults living with HIV in Northwest Ethiopia: a longitudinal data analysis. BMJ Open 2022;12:e055266. doi:10.1136/ bmjopen-2021-055266

\section{- Prepublication history and} additional supplemental material for this paper are available online. To view these files, please visit the journal online (http://dx.doi.org/10.1136/ bmjopen-2021-055266).

Received 07 July 2021 Accepted 13 January 2022

Check for updates

(C) Author(s) (or their employer(s)) 2022. Re-use permitted under CC BY-NC. No commercial re-use. See rights and permissions. Published by BMJ.

For numbered affiliations see end of article.

Correspondence to

Animut Alebel;

animut.a23@gmail.com

\section{ABSTRACT}

Objectives The first objective was to explore weight change in the first 2 years after antiretroviral therapy (ART) initiation in adults living with HIV. The second objective was to identify the predictors of weight change over time among adults living with HIV on ART.

Design An institution-based retrospective longitudinal study was conducted.

Setting The study was conducted at Debre Markos Comprehensive Specialized Hospital, Northwest Ethiopia. Participants The study included 848 randomly selected medical charts of adults living with HIV receiving ART between June 2014 and June 2020.

Primary and secondary outcomes The primary outcome was weight change in the first 2 years after ART initiation. The secondary outcome was to identify predictors of weight change. Association between predictor variables and weight change was assessed using an LMM. Variables with $p$ values $<0.05$ in the final model were considered as statistically significant predictors of weight change.

Results 0 848 study participants, more than half $(\mathrm{n}=499 ; 58.8 \%)$ were female. Participants' mean weight increased from $54.2 \mathrm{~kg}(\mathrm{SD} \pm 9.6 \mathrm{~kg})$ at baseline to $59.5 \mathrm{~kg}$ $(\mathrm{SD} \pm 10.7 \mathrm{~kg})$ at the end of follow-up. Duration of time on ART, sex, WHO clinical disease staging, functional status, nutritional status and presence of opportunistic infections were significant predictors of weight change at ART initiation. Significant interaction effects were observed between time and sex, WHO clinical disease staging, functional status, isoniazid preventive therapy and nutritional status.

Conclusion We found a linear increment of weight over 24 months of follow-up. Rate of weight gain over time was lower in patients with advanced disease stage and working functional status, whereas weight gain rate was higher in male and underweight patients.

\section{INTRODUCTION}

HIV-associated weight loss and wasting syndrome are the most frequently occurring AIDS-defining conditions and are associated with a higher risk of mortality and morbidity. ${ }^{1-3}$ Conversely, weight gain after antiretroviral therapy (ART) initiation is a good prognostic sign and associated with
Strengths and limitations of this study

- One of the strengths of this study is its large sample size $(n=848)$, increasing precision.

- This study is the first of its kind to explore weight change in adults living with HIV in our study area.

- Longitudinal measurements on weight allowed us to thoroughly examine changes in weight over 2 years after antiretroviral therapy initiation.

- Due to the retrospective nature of the study design, some important factors, such as dietary habits, physical activity, viral load (available only for $15 \%$ of all patients) and smoking status, were not available.

- We were unable to determine the anatomical distribution of weight gain, as data on body composition were not available.

The generalisability of our results to other settings, particularly to developed countries, could be limited because we have defined adulthood as age $\geq 15$ years.

lower risk of mortality in underweight and normal-weight patients. ${ }^{45}$ Though initiating highly active ART can significantly increase body weight and lean body mass, particularly within the first year, ${ }^{6-8}$ the mechanisms are not fully understood. ${ }^{9}{ }^{10}$ Weight gain after ART initiation could be due to the reversal of HIV-related catabolic effects (return-tohealth). ART also reduces the occurrence and recurrence of opportunistic infections (OIs) and enhances gastrointestinal function, increasing appetite and nutrient absorption. ${ }^{11}$ It could also result from some antiretroviral regimens' side effects. ${ }^{12} 13$

Weight is one of the WHO's clinical staging parameters used to classify HIV-infected patients. ${ }^{14}$ Adult and adolescent patients with moderate unexplained weight loss $(5 \%-10 \%)$ are classified as stage II, patients with unexplained severe weight loss $(>10 \%)$ are classified as stage III, and those with HIV wasting syndrome are classified as stage $\mathrm{IV}^{15}$ In 
low-income and middle-income countries, where monitoring the immunological and virological responses of patients is challenging (as routine viral load and CD4 cell count tests are expensive or simply unavailable) ${ }^{16}$ regular weight measurement is one of the most cost-effective tools used to monitor patients' clinical responses to ART. ${ }^{17}$

Current Ethiopian ART treatment guidelines recommend that weight must be measured and recorded at each ART visit, demonstrating the importance of weight control. ${ }^{15}$ However, these guidelines do not discuss what constitutes an optimal weight gain after ART initiation in this population. Moreover, even if weight gain after ART initiation is common, not all patients gain weight, and gains vary meaningfully across individuals. ${ }^{11} 1819$ Longitudinal studies investigating weight change over time after initiating ART are essential to inform treatment guidelines. Additionally, identifying modifiable risk factors of weight gain in this population can help to improve the overall treatment outcomes. However, studies on longitudinal weight change after ART initiation among adults living with HIV in Ethiopia are scarce. Due to this, evidence-based weight management guidelines and recommendations are not available in this population in the context of Ethiopia, as mentioned above. This study explored weight change in the first 2 years after ART initiation among adults living with HIV. The findings of this study will assist decision-makers, clinicians and programme planners to improve the quality of HIV patient care by enhancing the understanding of weight changes after initiating ART. Findings may also assist both adults living with HIV and clinicians in managing weight, particularly in resource-limited stings, including Ethiopia. In such settings, access to laboratory tests are limited; identifying simple and cost-effective tools to monitor disease progression such as weight measurement is imperative.

\section{METHODS}

\section{Study setting, design, and period}

An institution-based retrospective longitudinal study was conducted among adults living with HIV receiving ART between June 2014 and June 2020 at Debre Markos Comprehensive Specialized Hospital (DMCSH), Northwest Ethiopia. DMCSH is located in the East Gojjam administrative zone, Northwest Ethiopia, $300 \mathrm{~km}$ from Addis Ababa, the capital city of Ethiopia. It is currently the only referral hospital in East Gojjam Zone, with a catchment population of more than 3.5 million people. The total recorded number of people living with HIV (PLHIV) having ART initiated at DMCSH between June 2014 and June 2020 was 1,209, of which 1177 (97.4\%) were aged $\geq 15$ years (adults). Despite ART care services are being uniform in all health facilities and provided by ART-trained persons, DMCSH hospital was selected because it provides ART follow-up and care services for a large proportion of HIV-positive patients (accounted for $36.6 \%$ (1209) of all patients) in the East Gojjam Zone.

\section{Study population}

All adults living with HIV receiving ART between June 2014 and June 2020, who had at least two weight measurements (two visits) during ART follow-ups at DMCSH were eligible for inclusion. In this study, adulthood was defined as patients $\geq 15$ years of age since this population is considered and treated as adults in Ethiopia for treatment purposes. Patients transferred into DMCSH from other health institutions without baseline information and pregnant women were excluded. Pregnant women were excluded as pregnancy leads to weight gain, and nutritional assessment for pregnant women differs from other adults living with HIV. ${ }^{20}$

\section{Sample size and sampling procedure}

The sample size was determined using a formula for an independent cohort study, using Open Epi V. $3^{21}$ by considering the following parameters: $\alpha$ of $5 \%$; power of $80 \%$; $\mathrm{Z}_{\alpha / 2}$ of $1.96 ; \mathrm{P}_{0}$ of $19 \% ; \mathrm{P}_{1}$ of $27 \%$; and $\mathrm{r}$ of $1: 1$. The values of parameters to calculate sample size were taken from a previously conducted study in Ethiopia. ${ }^{22}$ The calculated sample size was 802 . After considering $10 \%$ chart incompleteness, the final sample size was 892. Then, the study participants were selected using a computer-generated simple random sampling technique. A list containing the medical registration number of all adults living with HIV $(\mathrm{n}=1177)$ who started ART between June 2014 and June 2020 was obtained from the health management information system unit of the DMCSH. A random number was generated for each patient using Microsoft Excel. These numbers were used to randomly select a sample of 892 participants from all adults living with HIV who started ART at DMCSH between June 2014 and June 2020.

\section{Patient and public involvement statement}

Patients or the public were not involved in the design, or conduct, or reporting, or dissemination plans of our research.

\section{Data collection procedures}

Data abstraction tools were developed from the standard Ethiopian ART entry and follow-up forms currently used by Ethiopian hospitals to assure data quality. ${ }^{15}$ The tool included sociodemographic characteristics, clinical and immunological characteristics, follow-up characteristics, and longitudinal weight measurements. Laboratory tests and measurements recorded at ART initiation were the baseline values. Data were collected by two epidemiologists with master-level qualifications currently employed by DMCSH and specialised in HIV. An experienced biostatistician in secondary data collection supervised the data collection process.

\section{Variables of the study}

This study's outcome (dependent) variable was weight change in the first 2 years after ART initiation among adults living with HIV who started ART for the first time (treatment naïve). Weight was measured in kilogram $(\mathrm{kg})$ at ART initiation (baseline) and then measured 
repeatedly every 3 months for 24 months. The follow-up time was recorded in months from ART initiation until 24 months (early ART phase).

Predictor (independent) variables were sociodemographic variables, baseline immunological and clinical variables, and follow-up variables.

Sociodemographic variables included age, sex, level of education, residence, marital status, occupation, family size and HIV-status disclosure. Baseline immunological and clinical variables included baseline OIs, CD4 cell counts, WHO clinical disease staging, Hgb level, nutritional status, functional status, ART eligibility criteria, and baseline ART regimen.

Follow-up variables were OIs during follow-up, ART adherence, history of ART regimen change, taking co-trimoxazole preventive therapy (CPT), taking isoniazid preventive therapy (IPT), HIV treatment failure based on viral load, and length of time on ART.

\section{Operational definitions}

The WHO body mass index (BMI) classification for underweight was used, defined a BMI of less than 18.5 $\mathrm{kg} / \mathrm{m}^{2}$ as underweight. ${ }^{23}$

ART adherence was classified as good, fair or poor, according to the percentage of ART dosages taken, calculated from the total monthly dose of ART drugs $(n=60)$. Good was defined as compliance equal to or greater than $95 \%$ or $\leq 3$ missed doses per month; fair reflected 85\%-94\% compliance or between 4 and 8 missing doses per month; and poor reflected less than $85 \%$ compliance or $\geq 9$ missed doses per month. ${ }^{15}$

HIV treatment failures was classified as clinical, immunological and virological failure. Clinical failure is diagnosed when the patient developed new or recurrent clinical events indicating severe immunodeficiency (WHO clinical stage IV condition and certain WHO clinical stage III conditions such as pulmonary tuberculosis (TB) and severe bacterial infections) after 6 months of effective ART treatment. Immunological failure was diagnosed when a patient had a CD4 count at or below 250 cells $/ \mathrm{mm}^{3}$ following clinical failure or persistent CD4 levels below 100 cells $/ \mathrm{mm}^{3}$. Virological failure was diagnosed when the viral load was above or equal to 1000 copies/mL under ART based on two consecutive viral load measurements in 3 months apart, with adherence support following the first viral load test. ${ }^{15}$

Functional status was classified as working, ambulatory and bedridden. Working was defined as the capability of going out of home and participating in routine activities, including daily work. Ambulatory was defined as being capable of self-care and being able to use the toilet without support. Bedridden was defined as being unable to use the toilet without support. ${ }^{15}$

Loss to follow-up is defined as adults living with HIV missing an ART appointment for at least 1 month. ${ }^{15}$

According to WHO, anaemia is defined as haemoglobin levels less than $12 \mathrm{~g} / \mathrm{dL}$ in males and $<13 \mathrm{~g} / \mathrm{dL}$ in females. ${ }^{24}$
Total number of PLHIV started ART between June 2014 and June $2020(\mathrm{~N}=1,209)$

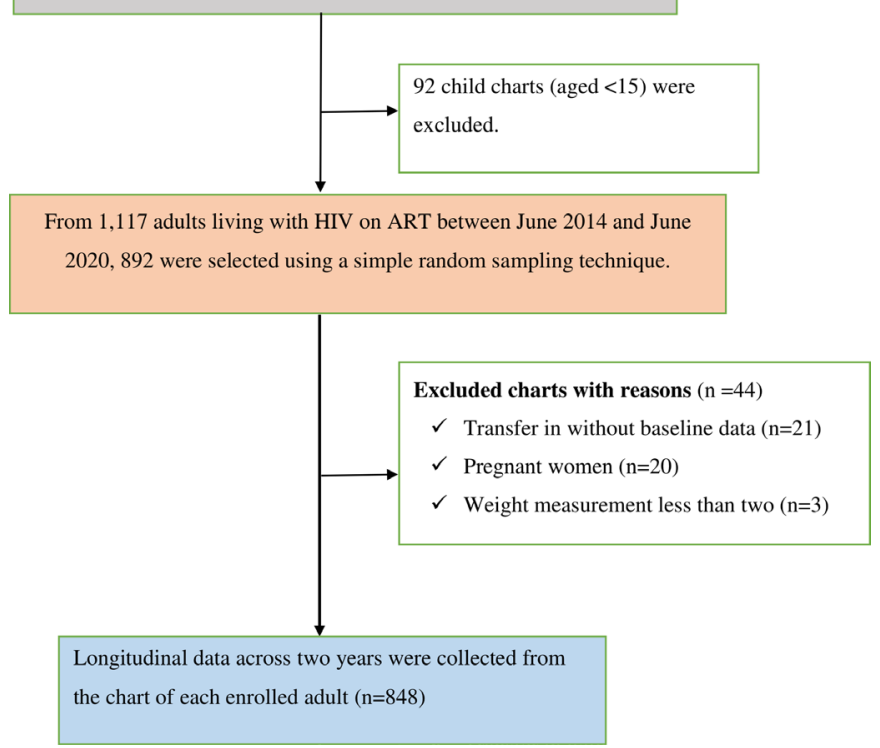

Figure 1 Flow chart showing the study participants recruitment process at Debre Markos Comprehensive Specialized Hospital in Northwest Ethiopia, between June 2014 and June 2020. ART, antiretroviral therapy PLHIV, people living with HIV.

\section{Statistical analyses}

Exploratory data analysis, including individual profile plots of weight for 50 (for better visualisation) randomly selected participants and the smoothed mean profile plot of all participants, were constructed. Since we used unbalanced data, a locally weighted scatterplot smoothing mean was used. In addition, the mean and SD of weight at each ART visit (every 3 months) were calculated. Normality assumption was checked using a $Q-Q$ plot. The autoregressive (AR1) covariance structure was used in the final model. The two nested models (a model with only random intercept and a model with both random intercept and slope) were compared using the likelihood ratio test. Finally, a linear mixed-effect model (LMM) with random intercept and slope was applied to address the repeated measurements. The model goodness of fit was also assessed using a model diagnostic plot. Variables with $\mathrm{p} \leq 0.25$ in the bivariate analysis were fitted into the multivariable analysis. For the LMM, statistical significance was set at $p<0.05$. All statistical analyses were conducted using R V.3.5.1 statistical software.

\section{RESULTS}

\section{Socio-demographic characteristics of participants}

The final sample consisted of 848 adult records (see figure 1$)$. Of these, more than half $(n=499 ; 58.8 \%)$ were female, and $45.3 \%(\mathrm{n}=393)$ were married. More than three-quarters $(\mathrm{n}=665 ; 78.4 \%)$ of the study participants were from urban areas, and the median age of the study participants was 32 (IQR: 26-40) years. Nearly onethird $(\mathrm{n}=258 ; 30.4 \%)$ of the participants had no formal 
Table 1 Sociodemographic characteristics of adults living with HIV on antiretroviral therapy at Debre Markos Comprehensive Specialized Hospital, Northwest Ethiopia $(\mathrm{n}=848)$

\begin{tabular}{lll}
\hline Variables & Frequency (N) & Percentage \\
\hline Residence & & \\
Urban & 665 & 78.4 \\
Rural & 183 & 21.6
\end{tabular}

\section{Age (years of age)}

\begin{tabular}{|c|c|c|}
\hline $15-24$ & 186 & 21.9 \\
\hline $25-34$ & 284 & 33.5 \\
\hline $35-44$ & 269 & 31.7 \\
\hline$\geq 45$ & 109 & 12.9 \\
\hline \multicolumn{3}{|l|}{ Sex } \\
\hline Male & 349 & 41.2 \\
\hline Female & 499 & 58.8 \\
\hline \multicolumn{3}{|l|}{ Marital status } \\
\hline Single & 155 & 18.3 \\
\hline Married & 393 & 45.3 \\
\hline Divorced & 217 & 25.6 \\
\hline Widowed & 83 & 9.8 \\
\hline \multicolumn{3}{|l|}{ Level of education } \\
\hline No formal education & 258 & 30.4 \\
\hline Primary & 219 & 25.8 \\
\hline Secondary & 224 & 26.4 \\
\hline Tertiary & 147 & 17.3 \\
\hline \multicolumn{3}{|l|}{ Occupation } \\
\hline Daily labourer & 139 & 16.4 \\
\hline Merchant & 168 & 19.8 \\
\hline Farmer & 119 & 14.0 \\
\hline Employed & 184 & 21.7 \\
\hline Student & 47 & 5.5 \\
\hline Housewife & 144 & 17.0 \\
\hline Others & 47 & 5.5 \\
\hline \multicolumn{3}{|l|}{ HIV-status disclosure } \\
\hline Disclosed & 569 & 67.1 \\
\hline Not disclosed & 279 & 32.9 \\
\hline \multicolumn{3}{|l|}{ Family size } \\
\hline$<3$ & 470 & 55.4 \\
\hline$\geq 3$ & 387 & 44.6 \\
\hline
\end{tabular}

education. Furthermore, more than two-thirds $(n=569$; $67.1 \%$ ) of the participants disclosed their HIV status (see table 1).

\section{Baseline clinical and immunological profile of participants}

Approximately 40\% (n=339) of the participants had baseline OIs (see table 2$)$, and more than a quarter $(n=228$; $26.9 \%)$ were underweight. The majority $(n=707 ; 83.4 \%)$ were categorised as having a working functional status.
Table 2 Baseline clinical and immunological profile of adults living with HIV on ART at Debre Markos Comprehensive Specialized Hospital, Northwest Ethiopia $(n=848)$

\begin{tabular}{|c|c|c|}
\hline Variables & Frequency (n) & Percentage \\
\hline \multicolumn{3}{|l|}{ Baseline Ols } \\
\hline Yes & 339 & 39.9 \\
\hline No & 509 & 60.1 \\
\hline \multicolumn{3}{|l|}{ Baseline nutritional status } \\
\hline Underweight & 228 & 26.9 \\
\hline Normal-weight & 620 & 73.1 \\
\hline \multicolumn{3}{|l|}{ Functional status } \\
\hline Working & 707 & 83.4 \\
\hline Ambulatory/bedridden & 141 & 16.6 \\
\hline \multicolumn{3}{|l|}{ CD4 cell count } \\
\hline $\begin{array}{l}\text { Severe immunodeficiency } \\
\left(\text { CD4 <200 cells } / \mathrm{mm}^{3}\right)\end{array}$ & 406 & 63.6 \\
\hline $\begin{array}{l}\text { Mild immunodeficiency } \\
\left(C D 4 \geq 200 \text { cells } / \mathrm{mm}^{3}\right)\end{array}$ & 232 & 36.4 \\
\hline WHO clinical staging & & \\
\hline
\end{tabular}

Mild disease stage (stage I $612 \quad 72.2$ and II)

\begin{tabular}{lcc}
$\begin{array}{l}\text { Advanced disease stage } \\
\text { (stage III and IV) }\end{array}$ & 236 & 27.8 \\
\hline $\begin{array}{l}\text { Haemoglobin level } \\
\text { Anaemic }\end{array}$ & 164 & 20.6 \\
\hline $\begin{array}{l}\text { Non-anaemic } \\
\text { ART eligibility criteria }\end{array}$ & 634 & 79.4 \\
\hline $\begin{array}{l}\text { Immunological/clinical } \\
\text { Test and treat }\end{array}$ & 378 & 44.6 \\
\hline $\begin{array}{l}\text { Baseline ART regimens } \\
\text { Efavirenz base }\end{array}$ & 470 & 55.4 \\
\hline $\begin{array}{l}\text { Nevirapine or dolutegravir } \\
\text { base }\end{array}$ & 66 & 92.2 \\
\hline
\end{tabular}

ART, antiretroviral therapy; OI, opportunistic infection.

Immunologically, $63.6 \%(\mathrm{n}=406)$ of the participants had severe immunodeficiency $\left(\mathrm{CD} 4<200\right.$ cell $\left./ \mathrm{m}^{3}\right)$. Clinically, $72.2 \%(\mathrm{n}=612)$ of participants were classified as mild disease stage (WHO stage I and II). Majority ( $\mathrm{n}=634$; $79.4 \%$ ) participants were non-anaemic at ART initiation. More than half $(\mathrm{n}=470 ; 55.4 \%)$ of the study participants commenced ART through a test and treat approach.

\section{Follow-up characteristics of participants}

The minimum and maximum length of time on ART for the study participants were 6 months (two visits) and 24 months, respectively. The median length of time on ART for the entire cohort was 12 months (IQR: 6-18). Almost one-third $(\mathrm{n}=269 ; 31.7 \%)$ of the participants developed OIs during the follow-up period. Three-quarters $(\mathrm{n}=637$; $75.1 \%$ ) of the participants had good adherence to their 
Table 3 Follow-up characteristics of adults living with HIV on ART at Debre Markos Comprehensive Specialized Hospital, Northwest Ethiopia $(n=848)$

\begin{tabular}{lll}
\hline Variables & Frequency (n) & Percentage \\
\hline Ols during follow-up & & \\
Yes & 269 & 31.7 \\
No & 579 & 68.3 \\
\hline ART adherence & & \\
Good & 637 & 75.1 \\
\hline Fair/ poor & 211 & 24.9 \\
Regimen change & & \\
Yes & 266 & 31.4 \\
No & 582 & 68.6 \\
\hline Taking IPT & & \\
Yes & 530 & 62.5 \\
\hline No & 318 & 37.5 \\
\hline Taking CPT & & \\
Yes & 621 & 73.2 \\
No & 227 & 26.8 \\
\hline HIV treatment failure & & 2.7 \\
Yes & 23 & 97.3 \\
\hline No & 825 & \\
\hline NRT antrovita & & \\
\hline
\end{tabular}

ART, antiretroviral therapy; CPT, co-trimoxazole preventive therapy; IPT, isoniazid preventive therapy; OI, opportunistic infection.

ART medication. Moreover, $62.5 \%(\mathrm{n}=530)$ of the participants took prophylaxis for TB prevention (IPT). CPT was given to $73.2 \% \quad(n=621)$ of the participants. Finally, $2.7 \%(n=23)$ of participants had HIV treatment failure (see table 3 ).

\section{Exploratory data analysis}

The minimum and the maximum recorded weights throughout the follow-up period were $25 \mathrm{~kg}$ and $98 \mathrm{~kg}$, respectively. Participants' mean weight increased from $54.2 \mathrm{~kg}(\mathrm{SD} \pm 9.6 \mathrm{~kg})$ at baseline to $59.5 \mathrm{~kg}(\mathrm{SD} \pm 10.7 \mathrm{~kg})$ at the end of follow-up. The average monthly weight gain was slightly higher $(0.33 \mathrm{~kg} /$ month $)$ in the first year as compared with the second year $(0.12 \mathrm{~kg} /$ month) (see table 4). The individual profile plots of 50 participants showed that considerable variability of weight change was observed between individuals (see online supplemental file 1). Furthermore, the smoothed mean profile plot of all participants indicated a linear increment of weight over time (see online supplemental file 2).

\section{Predictors of weight change}

Initially, a bivariable analysis was conducted, and variables with $p$ values $\leq 0.25$ were included in the multivariable analysis. As presented in table 5, the output from a multivariable LMM shows that duration of time on ART, sex, WHO clinical disease staging, functional status, nutritional status and presence of OIs were factors significantly
Table 4 Mean and SD of weight at each visit among adults living with HIV on antiretroviral therapy at Debre Markos Comprehensive Specialized Hospital, Northwest Ethiopia

\begin{tabular}{llc}
\hline Follow-up period (month) & (n) Weight (in kg, mean \pm SD)) \\
\hline Baseline & 848 & $54.2( \pm 9.6)$ \\
3rd month & 848 & $55.7( \pm 9.8)$ \\
6th month & 779 & $56.7( \pm 9.9)$ \\
9th month & 649 & $57.6( \pm 10.02)$ \\
12th month & 590 & $58.1( \pm 10.1)$ \\
15th month & 543 & $58.4( \pm 10.2)$ \\
18th month & 509 & $58.7( \pm 10.3)$ \\
21st month & 484 & $58.9( \pm 10.4)$ \\
24th month & 445 & $59.5( \pm 10.7)$ \\
\hline
\end{tabular}

associated with weight change at ART initiation. Statistically significant interaction effects were observed between time and several variables, including sex, WHO clinical disease staging, functional status, IPT and nutritional status. Specifically, with a 1 month increase in ART treatment duration, mean body weight increased by $0.43 \mathrm{~kg}$ ( $\beta=0.43,95 \%$ CI 0.35 to 0.5 ). The mean weight of male participants at ART initiation was $4.8 \mathrm{~kg}$ higher than female participants $(\beta=4.8,95 \%$ CI 3.5 to 6.0 ), and the rate of weight gain over time in male participants was $0.07 \mathrm{~kg} /$ month higher than female participants $(\beta=0.07$, $95 \%$ CI 0.02 to 0.11 ). The mean weight of patients with advanced disease stage was $2.6 \mathrm{~kg}$ lower than patients with mild disease stage at ART initiation $(\beta=-2.6,95 \% \mathrm{CI}-4.2$ to -1.0 ), and the rate of weight gain was $0.08 \mathrm{~kg} / \mathrm{month}$ less in patients with advanced disease stage than those with mild disease stage ( $\beta=-0.08,95 \%$ CI -0.14 to -0.02$)$.

The average weight of participants presented with working functional status was $3.9 \mathrm{~kg}$ higher than the average weight of participants presented with ambulatory/bedridden functional status $(\beta=3.9,95 \%$ CI 2.2 to 5.7) at ART initiation. However, over time, the monthly weight gain rate in participants with working functional status was $0.08 \mathrm{~kg} /$ month less than participants with ambulatory/bedridden functional status $(\beta=-0.08$, $95 \%$ CI -0.16 to -0.01$)$. The mean weight of normal weight participants was estimated to be $8.6 \mathrm{~kg}$ higher than underweight $\left(\mathrm{BMI}<18.5 \mathrm{~kg} / \mathrm{m}^{2}\right)$ participants at baseline ( $\beta=8.8,95 \%$ CI 7.1 to 10.1$)$. However, the rate of weight gain over time in normal-weight participants was $0.11 \mathrm{~kg}$ / month less than their underweight counterparts $(\beta=-0.11$, $95 \%$ CI -0.17 to -0.06$)$. At ART initiation, the average weight in patients presenting with OIs was $2.6 \mathrm{~kg}$ less than the average weight of patients presenting without OIs ( $\beta=-2.6,95 \%$ CI -3.9 to -1.3$)$. However, no statistically significant difference was observed in the monthly weight gain rate over time between patients presenting with OIs and without OIs. There was no significant difference of mean weight between patients who took IPT and those who did not take IPT at baseline, but there was a higher rate of weight gain among participants who did not take 
Open access

Table 5 Multivariable linear mixed effect model to identify predictors of weight change among adults living with HIV on ART at Debre Markos Comprehensive Specialized Hospital, Northwest Ethiopia

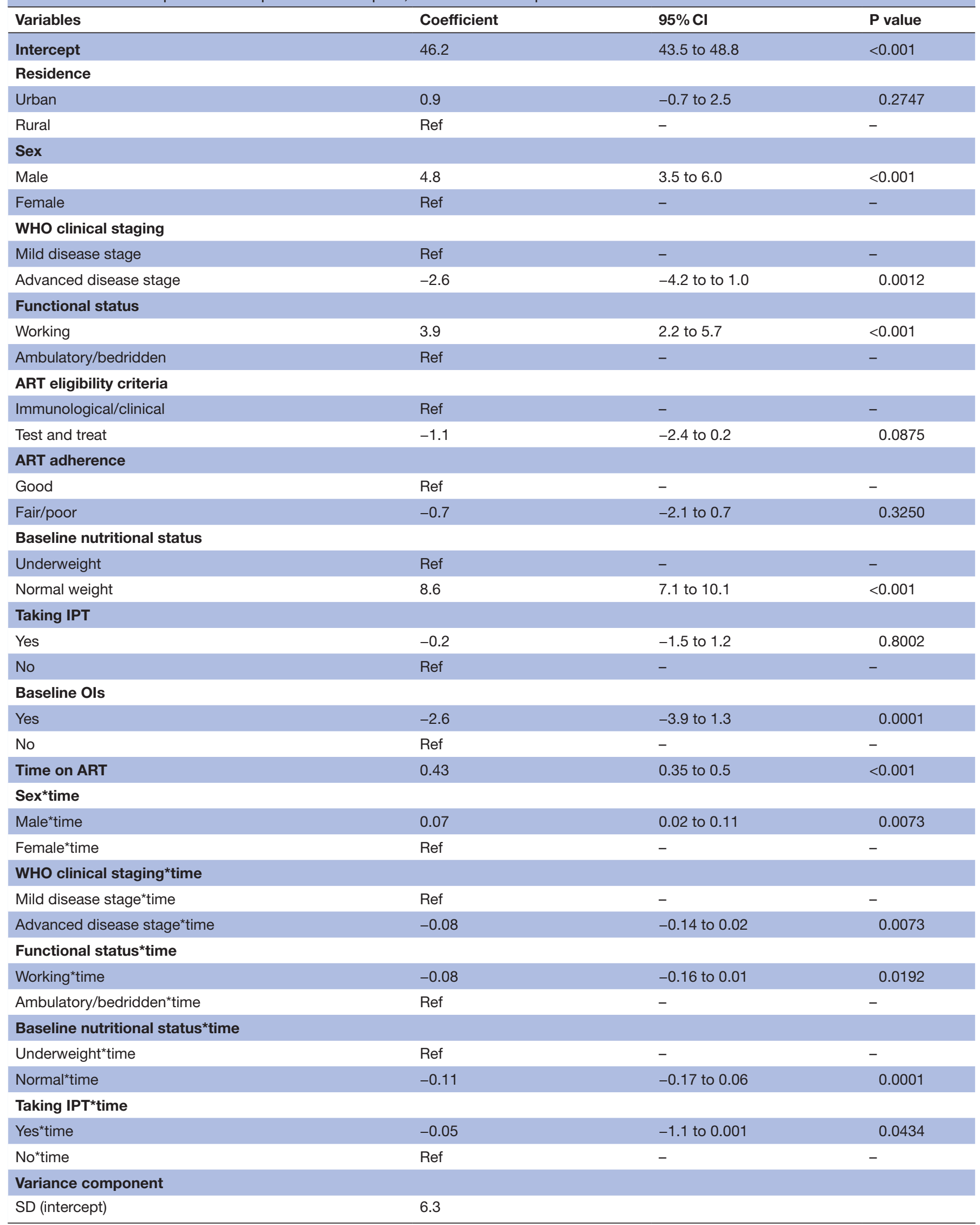


Table 5 Continued

\begin{tabular}{lll}
\hline Variables & Coefficient & 95\% Cl \\
\hline SD (time) & 0.13 & P value \\
SD (residual) & 5.0 \\
Corr (intercept) & 0.343 & \\
\hline
\end{tabular}

ART, antiretroviral therapy; IPT, isoniazid preventive therapy; OI, opportunistic infection.

IPT compared with those who took IPT $(\beta=-0.05,95 \%$ CI -1.1 to -0.001 ) (see table 5).

\section{DISCUSSION}

In this longitudinal study of 848 participants, we found a linear increment of weight over 24 months of follow-up, with a higher rate of weight gain in the first 12 months. This study also showed that the duration of time on ART has a positive association with weight gain. The mean weight at ART initiation and the rate of weight gain over time was higher in male participants than female participants. The mean weight at ART initiation and weight gain rate over time was lower in patients with advanced disease stage than in patients with mild disease stage. Normal-weight patients had a higher mean weight at ART initiation but less weight gain over time than underweight patients. In addition, patients with working functional status had a higher mean weight at ART initiation but a lower rate of weight gain over time, compared with participants with ambulatory or bedridden functional status. Furthermore, patients presenting with OIs had less mean weight at ART initiation than patients presenting without OIs. However, no statistically significant difference was observed over time in the monthly weight gain rate between patients presenting with and without OIs. Finally, at ART initiation, there was no significant difference in mean body weight between patients who received IPT and those who did not. However, the rate of weight gain was higher in participants who did not take IPT than in those who took IPT.

In this study, patients experienced a slightly higher weight gain rate in the first year of ART than in the second year $(0.33 \mathrm{~kg} /$ month vs $0.12 \mathrm{~kg} /$ month $)$. Similar patterns of higher weight gain in the first year of ART treatment were noted in previous studies conducted in similar low resource settings,${ }^{25}$ including Vietnam, ${ }^{18}$ and Cambodia and Kenya. ${ }^{4}$ Although the exact mechanisms of weight gain following ART remain unclear, reasons may include reversing HIV-related catabolic effects (return-to-health) and reducing the basal metabolic rate due to viral load suppression. ${ }^{26}$ ART also significantly reduces the occurrence and recurrence of OIs and enhances gastrointestinal function, increasing appetite and nutrient absorption. ${ }^{11}$ This study's finding of a 1 month mean body weight increase of $0.43 \mathrm{~kg}$ during ART treatment is consistent with prior Ethiopian studies. ${ }^{19} 27$ This may be explained by patients on ART for a longer period demonstrating higher levels of healthy practices, including ART adherence and social support, thereby enhancing clinical outcomes. ${ }^{28}$

Men had a higher mean weight at baseline and a higher rate of weight gain over time than women. While this finding is consistent with a previous Ethiopian study, ${ }^{19}$ it contradicts previous studies done elsewhere. ${ }^{511}$ Gender differences in weight gain might be associated with hormonal differences, and a higher likelihood of female patients living with HIV developing psychosocial issues such as anxiety and depression, negatively affecting body weight. ${ }^{29}{ }^{30}$ In addition, a meta-analysis showed that the proportion of women reporting $90 \%$ adherence to prescribed ART was lower than that of their male counterparts. ${ }^{31}$ Furthermore, lower weight gain in females might be due to higher levels of food insecurity among females in low-income and middle-income countries. ${ }^{32} 33$ This implies that gender-specific interventions and close follow-up are needed to improve weight among patients living with HIV on ART.

The mean weight of normal-weight participants was higher than underweight participants at baseline. However, the rate of weight gain over time was higher in underweight participants compared with their normal-weight counterparts, consistent with findings in previous studies. ${ }^{7345}$ This may be explained by underweight patients benefiting more directly from nutritional improvements resulting from ART initiation, such as increased nutritional intake and absorption by decreasing the occurrence and recurrence of OIs. ${ }^{36}$ Moreover, underweight PLHIV are eligible for nutritional supplements, ${ }^{37}$ as nutritional supplements in this population significantly increase weight. ${ }^{38}$ Thus, the weight of underweight patients can be further improved by providing appropriate nutritional education, as recommended by the Ethiopian ART guidelines. ${ }^{15}$

This study also found that participants in advanced disease stages had a lower mean weight at baseline and gained less weight over time than participants presented with mild disease stage. This finding is supported by prior studies done in low-resource settings. ${ }^{25} 27$ Poor weight gain in patients with advanced disease stages might be due to (undiagnosed) OIs, especially $\mathrm{TB}$, or high energy expenditure due to increased metabolic demand. Reported energy requirements for symptomatic adults living with HIV increased by $20 \%-30 \%$ compared with a $10 \%$ increase in asymptomatic adults living with HIV. ${ }^{39}$ 
Furthermore, the most common cause of swallowing difficulty, like oesophageal candidiasis, is a defining characteristic of stage IV, while unexplained chronic diarrhoea and pulmonary TB are the main clinical manifestation of stage III. ${ }^{15}$ These comorbidities indicate that weight management of HIV patients with advanced disease stages need special attention and can be addressed by preventing and treating OIs, improving ART adherence, and providing counselling to improve diet by consuming locally available foods.

At ART initiation, the mean weight was lower in patients presenting with OIs compared with patients without OIs, but no statistically significant difference was observed over time. OIs cause weight loss in PLHIV through impaired nutrient absorption due to chronic diarrhoea or intestinal tract damage, or reduced dietary intake due to oral thrush and oesophageal candidiasis. ${ }^{40}$ Moreover, patients presenting with OIs, especially TB, could have an inadequate response to ART due to common complications in people starting ART with coinfections and comorbidities. ${ }^{41}$ Our results suggested that if clinicians are proactive in prevention and treatment of OIs as early as possible, they could significantly improve the weight trajectory of HIV-infected patients on ART.

The average weight of participants with working functional status was higher than participants with ambulatory or bedridden functional status at ART initiation. However, the weight gain rate over time in participants with working functional status was less than participants with ambulatory or bedridden functional status. This finding is consistent with studies conducted elsewhere ${ }^{19} 42$ and likely reflects HIV disease severity before ART initiation and the return to health in patients with more advanced disease. Finally, there is a higher rate of weight gain among participants who did not take IPT compared with those who took IPT. This finding is directly associated with disease progression, as IPT is indicated for HIV-positive patients with advanced disease but has no confirmed TB infection. ${ }^{1541}$ In addition, it may be directly related to the side effects of IPT, such as vomiting, loss of appetite and nausea which are the most common side effects of IPT. ${ }^{43}$

\section{CONCLUSION}

In this study, we found a linear increment of weight over 24 months of follow-up, with a higher rate of weight gain in the first 12 months. Over time, the rate of weight gain was lower in patients with advanced disease stage, who took IPT and working functional status. However, male and underweight patients had a higher rate of weight gain. The clinical implication is that health professionals must continuously monitor and assess patients' weight with poor clinical conditions (ie, patients presented with advanced disease stage and OIs) to find potential reasons for failure to gain weight. Further studies examining the effects of weight gain on treatment outcomes by incorporating some variables, such as dietary and exercise habits, are needed.

\section{Author affiliations}

${ }^{1}$ College of Health Science, Debre Markos University, Debre Markos, Ethiopia ${ }^{2}$ School of Public Health, Faculty of Health, University of Technology Sydney, Ultimo, New South Wales, Australia

${ }^{3}$ School of Public Health and Social Work, Faculty of Health, Queensland University of Technology, Kelvin Grove, Queensland, Australia

${ }^{4}$ College of Nursing, University of Saskatchewan, Saskatoon, Saskatchewan, Canada

${ }^{5}$ School of Life Sciences and Bioengineering, Nelson Mandela African Institute of Science and Technology, Arusha, Tanzania

Correction notice This article has been corrected since it was first published. The abstract section has been updated.

Acknowledgements We would like to acknowledge the data collectors and their supervisors.

Contributors AA: conception of the research idea, design, analysis, interpretation and drafting the manuscript. DD, PMP and DS: design, interpretation of results, reviewing and editing the manuscript. All authors have read and approved the final manuscript. AA is responsible for the overall content as guarantor.

Funding The authors have not declared a specific grant for this research from any funding agency in the public, commercial or not-for-profit sectors.

Competing interests None declared.

Patient consent for publication Not applicable.

Ethics approval This study does not involve human participants.

Provenance and peer review Not commissioned; externally peer reviewed.

Data availability statement Data are available upon reasonable request. Data used for this study will be available upon request of the corresponding author.

Supplemental material This content has been supplied by the author(s). It has not been vetted by BMJ Publishing Group Limited (BMJ) and may not have been peer-reviewed. Any opinions or recommendations discussed are solely those of the author(s) and are not endorsed by BMJ. BMJ disclaims all liability and responsibility arising from any reliance placed on the content. Where the content includes any translated material, BMJ does not warrant the accuracy and reliability of the translations (including but not limited to local regulations, clinical guidelines, terminology, drug names and drug dosages), and is not responsible for any error and/or omissions arising from translation and adaptation or otherwise.

Open access This is an open access article distributed in accordance with the Creative Commons Attribution Non Commercial (CC BY-NC 4.0) license, which permits others to distribute, remix, adapt, build upon this work non-commercially, and license their derivative works on different terms, provided the original work is properly cited, appropriate credit is given, any changes made indicated, and the use is non-commercial. See: http://creativecommons.org/licenses/by-nc/4.0/.

ORCID iD

Animut Alebel http://orcid.org/0000-0003-2822-2062

\section{REFERENCES}

1 Mangili A, Murman DH, Zampini AM, et al. Nutrition and HIV infection: review of weight loss and wasting in the era of highly active antiretroviral therapy from the nutrition for healthy living cohort. Clin Infect Dis 2006;42:836-42.

2 Tang AM, Forrester J, Spiegelman D, et al. Weight loss and survival in HIV-positive patients in the era of highly active antiretroviral therapy. J Acquir Immune Defic Syndr 2002;31:230-6.

3 Wanke CA, Silva M, Knox TA, et al. Weight loss and wasting remain common complications in individuals infected with human immunodeficiency virus in the era of highly active antiretroviral therapy. Clin Infect Dis 2000;31:803-5.

4 Madec Y, Szumilin E, Genevier C, et al. Weight gain at 3 months of antiretroviral therapy is strongly associated with survival: evidence from two developing countries. AIDS 2009;23:853-61.

5 Yuh B, Tate J, Butt AA, et al. Weight change after antiretroviral therapy and mortality. Clin Infect Dis 2015;60:1852-9.

6 Koethe JR, Jenkins CA, Lau B, et al. Rising obesity prevalence and weight gain among adults starting antiretroviral therapy in the United States and Canada. AIDS Res Hum Retroviruses 2016;32:50-8.

7 Achhra AC, Mocroft A, Reiss P, et al. Short-term weight gain after antiretroviral therapy initiation and subsequent risk of cardiovascular disease and diabetes: the D:A:D study. HIV Med 2016;17:255-68. 
8 Bakal DR, Coelho LE, Luz PM, et al. Obesity following ART initiation is common and influenced by both traditional and HIV-/ART-specific risk factors. J Antimicrob Chemother 2018;73:2177-85.

9 Rao SG, Galaviz KI, Gay HC, et al. Factors associated with excess myocardial infarction risk in HIV-infected adults: a systematic review and meta-analysis. J Acquir Immune Defic Syndr 2019;81:224-30.

10 Lang S, Mary-Krause M, Cotte L, et al. Increased risk of myocardial infarction in HIV-infected patients in France, relative to the general population. AIDS 2010;24:1228-30.

11 Sax PE, Erlandson KM, Lake JE, et al. Weight gain following initiation of antiretroviral therapy: risk factors in randomized comparative clinical trials. Clin Infect Dis 2020;71:1379-89.

12 Taramasso L, Ricci E, Menzaghi B, et al. Weight gain: a possible side effect of all antiretrovirals. Open Forum Infect Dis 2017;4:ofx239.

13 Bhagwat P, Ofotokun I, McComsey GA. Predictors of severe weight/ body mass index gain following antiretroviral initiation. Poster presented at Conference on Retrovirus and Opportunistic Infections, Seattle, Washington, 2017.

14 Weinberg JL, Kovarik CL. The WHO clinical staging system for HIV/ AIDS. AMA Journal of Ethics 2010;12:202-6.

15 Ministry of Health Ethiopia. National comprehensive HIV prevention, care and treatment training for health care providers. Addis Ababa, Ethiopia, 2017.

16 Loveday M, Scott V, McLoughlin J, et al. Assessing care for patients with TB/HIV/STI infections in a rural district in KwaZulu-Natal. $S$ Afr Med J 2011;101:887-90.

17 Colebunders R, Moses KR, Laurence J, et al. A new model to monitor the virological efficacy of antiretroviral treatment in resourcepoor countries. Lancet Infect Dis 2006;6:53-9.

18 Tang AM, Sheehan HB, Jordan MR, et al. Predictors of weight change in male HIV-positive injection drug users initiating antiretroviral therapy in Hanoi, Vietnam. AIDS Res Treat 2011;2011:890308.

19 Weldesenbet AB, Ayele TA, Sisay MM, et al. Predictors of change in weight among people living with HIV on antiretroviral treatment in West Hararghe zone, Ethiopia: a retrospective longitudinal study. Hiv Aids 2020;12:373-80.

20 Ververs M-T, Antierens A, Sackl A, et al. Which anthropometric indicators identify a pregnant woman as acutely malnourished and predict adverse birth outcomes in the humanitarian context? PLoS Curr 2013;5. doi:10.1371/currents.dis.54a8b618c1bc031ea140e3f2 934599c8. [Epub ahead of print: 07 Jun 2013].

21 Kelsey JL, Whittemore AS, Evans AS. Methods in observational epidemiology: monographs in epidemiology and biostatistics, 1996.

22 Teshale AB, Tsegaye AT, Wolde HF. Incidence and predictors of loss to follow up among adult HIV patients on antiretroviral therapy in University of Gondar comprehensive specialized Hospital: a competing risk regression modeling. PLoS One 2020;15:e0227473.

23 Weir CB, Jan A. BMI classification percentile and cut off points. In: StatPearls. Treasure Island, FL: StatPearls Publishing Copyright ( ${ }^{\text {, }}$, 2021.

24 World Health Organization. Haemoglobin concentrations for the diagnosis of anaemia and assessment of severity, 2011.

25 Huisin 't Veld D, Balestre E, Buyze J, et al. Determinants of weight evolution among HIV-positive patients initiating antiretroviral treatment in low-resource settings. J Acquir Immune Defic Syndr 2015;70:146-54.

26 Bourgi K, Jenkins CA, Rebeiro PF, et al. Weight gain among treatment-naïve persons with HIV starting integrase inhibitors compared to non-nucleoside reverse transcriptase inhibitors or protease inhibitors in a large observational cohort in the United States and Canada. J Int AIDS Soc 2020;23:e25484.
27 Reda AA, Biadgilign S, Deribew A, et al. Predictors of change in CD4 lymphocyte count and weight among HIV infected patients on antiretroviral treatment in Ethiopia: a retrospective longitudinal study. PLoS One 2013;8:e58595.

28 Siril HN, Kaaya SF, Smith Fawzi MK, et al. Clinical outcomes and loss to follow-up among people living with HIV participating in the NAMWEZA intervention in Dar es Salaam, Tanzania: a prospective cohort study. AIDS Res Ther 2017;14:18.

29 Albert PR. Why is depression more prevalent in women? J Psychiatry Neurosci 2015;40:219-21.

30 Kuehner $\mathrm{C}$. Why is depression more common among women than among men? Lancet Psychiatry 2017;4:146-58.

31 Ortego C, Huedo-Medina TB, Santos P, et al. Sex differences in adherence to highly active antiretroviral therapy: a meta-analysis. AIDS Care 2012;24:1519-34.

32 Jung NM, de Bairros FS, Pattussi MP, et al. Gender differences in the prevalence of household food insecurity: a systematic review and meta-analysis. Public Health Nutr 2017;20:902-16.

33 Boneya DJ, Ahmed AA, Yalew AW. The effect of gender on food insecurity among HIV-infected people receiving anti-retroviral therapy: a systematic review and meta-analysis. PLoS One 2019;14:e0209903

34 Koethe JR, Lukusa A, Giganti MJ, et al. Association between weight gain and clinical outcomes among malnourished adults initiating antiretroviral therapy in Lusaka, Zambia. J Acquir Immune Defic Syndr 2010;53:507-13.

35 Crum-Cianflone N, Roediger MP, Eberly L, et al. Increasing rates of obesity among HIV-infected persons during the HIV epidemic. PLoS One 2010;5:e10106.

36 Günthard HF, Saag MS, Benson CA, et al. Antiretroviral drugs for treatment and prevention of HIV infection in adults: 2016 recommendations of the International antiviral Society-USA panel. JAMA 2016;316:191-210.

37 Mallewa J, Szubert AJ, Mugyenyi P, et al. Effect of ready-to-use supplementary food on mortality in severely immunocompromised HIV-infected individuals in Africa initiating antiretroviral therapy (REALITY): an open-label, parallel-group, randomised controlled trial. Lancet HIV 2018;5:e231-40.

38 PrayGod G, Friis H, Filteau S. Nutritional support to reduce mortality in patients with HIV? Lancet HIV 2018;5:e202-4.

39 Kosmiski L. Energy expenditure in HIV infection. Am J Clin Nutr 2011;94:1677S-82.

40 Evans D, Maskew M, Sanne I. Increased risk of mortality and loss to follow-up among HIV-positive patients with oropharyngeal candidiasis and malnutrition before antiretroviral therapy initiation: a retrospective analysis from a large urban cohort in Johannesburg, South Africa. Oral Surg Oral Med Oral Pathol Oral Radiol 2012;113:362-72.

41 World Health Organization. Consolidated guidelines on the use of antiretroviral drugs for treating and preventing HIV infection: recommendations for a public health approach, 2016. Available: https://apps.who.int/iris/bitstream/handle/10665/208825/ 9789241549684_eng.pdf [Accessed 20 Jun 2021].

42 Baraki AG, Gezie LD, Zeleke EG, et al. Body mass index variation over time and associated factors among HIV-positive adults on second-line art in north-west Ethiopia: a retrospective follow-up study. BMJ Open 2019;9:e033393.

43 Denholm JT, McBryde ES, Eisen DP, et al. Adverse effects of isoniazid preventative therapy for latent tuberculosis infection: a prospective cohort study. Drug Healthc Patient Saf 2014;6:145-9. 